\title{
Application of System Reliability Indices in Electric Power System
}

\author{
Ganiyu Adedayo Ajenikoko ${ }^{1}$, Ojerinde Adedapo Ibukunoluwa ${ }^{2}$, Adenle Musibau Shittu ${ }^{3}$ Ibitowa Michael ${ }^{4}$, \\ Yusuf Mukhtar ${ }^{5}$ \\ 1.2,Department of Electronic and Electrical Engineering, Ladoke Akintola University of Technology, \\ P.M.B, 4000, Ogbomoso, Nigeria
}

\begin{abstract}
System reliability indices deal with the adequacy of overall system supply and indicates the system behaviour and response. The index express interruption statistics in terms of the customers which can be an individual, firm, or organization that purchases electric services at one location under one rate classification, contract or schedule. The system reliability indices include: System Average Interruption Frequency Index (SAIFI), System Average Interruption Duration Index (SAIDI), Customer Average Interruption Duration Index (CAIDI), Average Service Availability Index (ASAI), Average Service Unavailability Index (ASUI), Expected Energy Not Supplied (EENS) and Average Energy Not Supplied (AENS). These indices are used as performance evaluation for power system reliability assessment. This assessment helps in system planning for long and short terms. This study therefore focuses reviewed past study on application of SAIFI, SAIDI and CAIDI for system reliability assessment on electric power system. These indices imply how often an average customer experiences sustained interruption over a predefined time of year and they are most used reliability indices for power system.
\end{abstract}

Keywords: Reliability Indices, SAIDI, SAIFI, CAIDI, ASAI, ASUI, AENS, Reliability Assessment.

DOI: $10.7176 / J E T P / 11-6-03$

Publication date: November $30^{\text {th }} 2021$

\section{INTRODUCTION}

Power system reliability is the ability of the system to provide adequate supply of electric power with satisfactory quality. The power system reliability is made up of both adequacy and security assessment [14]. System adequacy deals with the existence of sufficient generation, transmission and distribution facilities within the system to satisfy customer load demand. It is associated with the system steady state conditions and system planning for long and short terms. While system security involves the ability of the system to respond to disturbances and remain in secure operation and meeting the customer demand. In order to maintain the desired level of adequacy and to avoid excessive shortages, additional reserve must be maintained. In case of adequacy and security, the higher the reserve margin the higher the system reliability but at a substantial economic cost [1-6], [7], [9].

Managing bulk system reliability for utility is essential. However, there is the need for measurement of actual system reliability that provides a feedback to the planners on the performance of executed plans. This gives feedback to operation personnel on reliability effects of operating and maintenance practices [1]. The reliability of a network could be judged on the basis of reliability indices. Thus, the sustained interruption system reliability indices considered for measurement of actual system reliability on power system include: System Average Interruption Frequency Index (SAIFI), System Average Interruption Duration Index (SAIDI), Customer Average Interruption Duration Index (CAIDI), Average Service Availability Index (ASAI), Average Service Unavailability Index (ASUI), Expected Energy Not Supplied (EENS) and Average Energy Not Supplied (AENS) [2], [8], [17].

However, in this study, the application of SAIFI, SAIDI and CAIDI which are most used reliability indices for power system was reviewed. These reliability indices imply how often an average customer experiences sustained interruption over a predefined time of year and.

\section{A. System Average Interruption Frequency Index}

System Average Interruption Frequency Index (SAIFI) indicates the average frequency of sustained interruptions per customer over a predefined area [11-12], [19], [27]. The number of customers and the interruptions experienced by them vary from time to time. For instance, feeder SAIFI indicates the average number of interruptions a customer experience on a particular feeder in a year. Similarly SAIFI reported that a substation or a distribution system encloses the total customers in the service area. The System average interruption frequency index (SAIFI) is given by [10],[20], [30]

$$
\text { SAIFI }=\frac{\text { TotalNumberofCustomersinterruptions }}{\text { TotalNumberofCustomersServed }}
$$

In order to calculate the index, data of individual sustained interruptions in a year are required. For each of these interruptions, the number of customers affected comprises the customer interruptions for the particular outage. The denominator is the total number of customers in the service area under consideration. Thus, the SAIFI is represented by [21-22]:

$$
S A I F I=\frac{\sum N_{i}}{N_{T}}
$$

$\mathrm{N}_{\mathrm{i}}$ is the number of interrupted customers for each interruption event during the reporting period and $\mathrm{N}_{\mathrm{T}}$ is the total 
number of customers served in the area.

\section{B. System Average Interruption Duration Index}

System Average Interruption Duration Index (SAIDI) indicates the average time a customer has an interruption during a time cycle (1 year). It is usually specified in customer minutes or customer hours of interruption per year. SAIDI is the average interruption duration per customer served and it is determined by dividing the sum of all customer interruption durations during a year by the number of customers served. SAIDI is given by [26], [28-29].

$$
S A I D I=\frac{\sum \text { CustomerInterruptionDurations }}{\text { TotalNumberofCustomersServed }}
$$

SAIDI can be improved by reducing the number of interruptions or the duration of the interruptions. For a given service area, system average interruption duration index SAIDI is represented as given by [31-32]

$$
S A I D I=\frac{\sum r_{i} N_{i}}{N_{T}}
$$

where; $\mathrm{N}_{\mathrm{i}}$ is the number of interrupted customers for each interruption event during the reporting period, $\mathrm{N}_{\mathrm{T}}$ is the total number of customers served in the area and $r_{i}$ is restoration time for each interruption event. The number of customers affected and the time it took for the restoration for each interruption event are the parameters required to estimate the system average interruption duration index. The restoration time includes, the time taken to notice an outage, the time taken to locate and reach the location and the time to repair the fault [23], [27], [38].

\section{Customer Average Interruption Duration Index}

Customer Average Interruption Duration Index (CAIDI) is the average interruption duration for those customers interrupted during a year. It is determined by dividing the sum of all customer interruption durations by the number of customers experiencing one or more interruptions over a year period [18], [25].The index is the ratio of SAIDI to SAIFI as given in equations (2) and (4) respectively. It represents the average time taken to restore service to the customers when a sustained interruption occurs. CAIDI is given by [13].

$$
C A I D I=\frac{\text { CCustomerInterruptionDurations }}{\text { TotalNumberofCustomerInterruption }}
$$

The value of CAIDI for a given service area is given as:

$$
C A I D I=\frac{\sum r_{i} N_{i}}{\sum N_{i}}
$$

where; $\mathrm{N}_{\mathrm{i}}$ is the number of interrupted customers for each interruption event during the reporting period and $\mathrm{r}_{\mathrm{i}}$ is restoration time for each interruption event.

\section{OWER SYSTEM MAINTENANCE}

Maintenance management is an important driver for increasing power reliability. It includes all works performed to keep the physical distribution assets in operating conditions. This includes preventive, predictive and Reliability Centre Maintenance (RCM). RCM is a unique programative approach to predictive maintenance targeting just in the maintenance intervention to avoid failures and optimize costs. Maintenance management ensures the productivity of the utility by influencing the percentage of time that its physical assets are available to operate. This directly affects the financial and service performance of the Company [28], [33], [37].

The utility industry takes various preventive actions to minimize component failure rates, which have a direct impact on service reliability. The preventive actions at the distribution level consist of routine maintenance on testable and repairable components, replacement of non-repairable components, treeing, and installation of animal guards and cleaning of insulators. The maintenance actions can be considered to be the general monitoring, testing, and repairing of components that deteriorate due to aging and continuous operations [8], [15], [39].

Traditionally, most utilities follow a rigid maintenance schedule based either on a fixed time interval or on the number of operations for the equipment, or on a combination of both. Routine maintenance based on a fixed time schedule depends on the individual utility practices or the manufacturer's recommendations. Non-repairable equipment will be replaced if it fails, or as it ages, if the expected failure rate exceeds an unacceptable value [34], [36], [39].

Today, due to increased economic pressures, utilities have been forced to reduce operation and maintenance costs. Thus, there is a need to perform maintenance at minimum cost without jeopardizing system reliability. One of the techniques has been to increase the time interval for routine maintenance and testing. Self-diagnostic capability of new protective devices contributed to the justification for this increase in maintenance. In the power industry, most efforts have focused on data gathering and the application of reliability measures has been heuristic [7], [16], [24].

Reliability analysis has been developed which calculates the contributions of each line section, and its associated equipment, to the overall reliability indices. Such data assist engineer in evaluating the impact of various proposed maintenance schedules. Protective devices also play a fundamental role in improving power system reliability. Automatic line sectionalizing devices such as line reclosers, interrupters, sectionalizers and fuses reduced the total number of customers affected for a single outage by automatically isolating the faulted section. This reduces the frequency of outages for customers on the source side of the device and also reduces the duration 
of outages by expediting the task of locating the faulted feeder section.

\section{REVIEW OF RELATED WORKS}

Wang et al. (2000) presented time sequential Monte-Carlo simulation technique for evaluating probability distributions of distribution system reliability indices. An event based index histogram shows the probabilities of parameters related to specific failure events. An annual index histogram presents the probabilities of indices created by aggregating the event-based parameters over a year. The results showed that the time varying cost model (TVCM) has relatively slight impacts on the probability distributions of the load point and system indices. The method used may result in unnecessary additional cost [39].

Elena and Vitaly (2001) investigated a new reliability index for the Multi-State System (MSS) reliability using mathematical tool of logic differential calculus of Multi-Valued Logic (MVL) function for calculation of the reliability indices. These indices allowed investigating an outcome of a modification of a serviceability level of a separate system component for system reliability. The results showed that failures in protection system can downgrade the system reliability level as a result of the outages of intact equipment following the initial system disturbances making the stressed system situation even worse. The method used was not guaranteed to be optimal [12].

Dan (2003) presented a reliability analysis algorithm for large scale radially operated (with respect to substation), reconfigurable, electrical distribution systems. The algorithm took into account power equipment handling constraints and converged in a matter of seconds on systems containing thousands of components. Linked lists of segments were employed in obtaining the rapid convergence. A power flow calculation was used to check the power handling constraints. The result indicated that, placement of DG and its effect on reliability improved the reliability over a time varying load curve. Due to the fast convergence of the method used it could only be used for online application [10].

Neto et al. (2006) described a methodology to evaluate the impact of DG on the reliability indices of distribution networks considering the network constraints. The network constraints model used was based on a simplified version of the power summation load flow method and compensation techniques. The results obtained demonstrated that DG had a significant impact on the reliability indices of distribution networks. Thus, the method cannot provide the concrete information for real engineering decision making [27].

Sacket et al. (2007) described a methodology for evaluation of the reliability of a composite electrical power system considering voltage stability and continuation power flow taking into account the peak load and steady state stability limit. The voltage stability was obtained for the probable outage of transmission lines. The Loss of Load Probabilities (LLP) index was evaluated by merging the capacity probability with load model. The results showed that simulation was in close agreement with the analytical results. The implementation of the method used was very hard and complicated [35].

Hadow et al. (2012) evaluated the reliability of distribution power systems using Artificial Neural Network (ANN). ANN was used to predict the reliability of distribution power using historical data method constructed according to the back propagation learning rule. System indices such as SAIFI and SAIDI of real distribution system were computed and compared with results generated by network method. The result gave acceptable reliability indices and also found that the deviation of computed values by the method was less. The ANN approach demonstrated advantages over the network method. However, the ANN approach was time consuming and cannot be guaranteed for best configuration [21].

Ahadi et al. (2013) presented electric power distribution system reliability in smart grids, which incorporates the impact of smart monitoring on the overall system reliability using Markov method. The approach was applied to Roy Billinton Test System and implemented on IEEE 6-Bus system. The implementations indicated that using an appropriate set of the smart grid monitoring devices for power system components could virtually influence all the reliability indices although the amount of improvement varied between techniques. The result indicated that using smart monitoring significantly mitigated the values of SAIDI and CAIDI indices. However, the interruption frequency, SAIFI improvement remained almost the same regardless of the smart monitoring integration [3].

Gao et al. (2014) presented a method for reliability analysis of distribution systems with Distributed Generation (DG) using Bayesian network diagnostic inference. The reliability indices such as SAIFI, SAIDI, and CAIDI of a distribution system were computed and the effects of each component on the system reliability were presented. The results showed that indices were too sensitive to location, capacity and availability of DG units. Hence, the capacity of DG unit for the best location in a distribution system was obtained using the method. However, the shortcomings of traditional reliability assessment methods were not overcome. Thus, the method could not provide the concrete information for real engineering decision making [18].

Ge et al. (2014) presented the reliability assessment problem of low and high DG penetration level of active distribution system using Monte Carlo simulation method. The problem was formulated as a two-case program, the program of low penetration simulation and the program of high penetration simulation. The load shedding strategy and the simulation process were introduced during the process. Results indicated that the integration of 
DG improved the reliability of the system if the system was operated actively but the method could not guarantee the optimal solution for reliability stability in distribution network [19].

Gont and Worku (2014) presented the use of smart reclosers for improving reliability of a distribution system using WindMill software to verify the improvement of the reliability indices for the distribution system. The average frequency of interruption and average duration of interruption of the city grid was estimated respectively. The simulation result of the designed model with three reclosers in each feeder and tie-recloser between connected nearby feeders shows that the application of smart reclosers improved the reliability of the distribution network compared with the reliability ofexisting system. This indicated that there is a high unavailability of electric power in the distribution network. However, the comparative indices values for SAIFI and SAIDI was not specified [20].

Abdrabbi and Meglouli (2015) analyzed the reliability expression of different substation configurations in distribution system using Disjoint Sum of Product (DSOP) algorithm. The algorithm was synthesized and applied to determine the reliability expression of a substation and costs of different substation arrangements. The method was found to be significantly lower in comparison with the time consuming procedures of Monte Carlo-simulation solution. However, the method was not capable of handling and modelling a large, repairable system [1].

Bourezg and Meglouli (2015) presented a computerized and implemented algorithm, based on Disjoint Sum of Product (DSOP) algorithm for reliability in distribution system. The algorithm was synthesized and applied to determine the reliability expression of a substation, reliability indices and costs of different substation arrangements. The result indicated that the time consuming procedures of the DSOP solution generated for different substation arrangements was found to be significantly lower in comparison with the time consuming procedures of Monte Carlo-simulation solution. Then, the reliability of a radial distribution system was evaluated using DSOP solution. However, the technology of DSOP was tested while the technical impacts and economic impacts were not explained [9].

Mohan et al. (2015) used fuzzy value applied for every component related for calculation of the reliability indices such as SAIFI, SAIDI and CAIDI. The calculation of crisp value of normalized fuzzy values was carried out by defuzzification for power system planning. Each of the components related to reliability of distributed power system were taken separately. The result indicated that all the components were continuous with fuzzy value. However, the method was based on unrealistic assumptions [26].

Okorire et al. (2015) discussed the reliability of electric distribution network through the study of indicators of reliability analysis such as SAIDI, SAIFI and CAIDI. These reliability indices include measures of outage duration, frequency of outages, system availability and response time. Both narrative and quantitative reliability characterizations of distribution infrastructural outlays were employed in order to proffer sound operational philosophies aimed at insuring efficient, secure, reliable and high quality electricity delivery to consumers. However, the method was based on unrealistic assumptions [29].

Rajaiah et al. (2015) analyzed the reliability of electrical distribution network based on load and sustained interruptions in ensuring quality service for customers. The performance of the duration and frequency of customer interruptions such as SAIFI, SAIDI, CAIDI and ASAI was examined and measured at various system levels. The most commonly used indices are SAIFI, SAIDI, CAIDI and ASAI. The results provided information about average system performance for decision making but the method was only based on assumptions [32].

Abul'Wafa (2016) developed a Genetic Algorithm (GA) optimization technique to improve automation, reclosing and switching capacity of the feeder for the reliability of distribution system using SAIDI, SAIFI, CAIDI and ASAI to evaluate the reliability of the distribution system. Reliability improvements were designed under constraints of feeder reliability indices SAIDI and SAIFI because of its high installed supply capacity and high record of interruption. The result showed that implementation of GA improved the reliability of vast and complex distribution networks. The automation reclosing and switching optimization simulation results were achieved at low annual extra cost. However the result of SAIFI and SAIDI were not significant [2].

Elkadeem et al. (2016) presented a generic framework and strategy for the implementation of Distribution Automation System (DAS) using Fault Location, Isolation and Service Restoration (FLISR) for self-healing and reliability improvement of distribution networks. The FLISR was implemented on an underground Medium Voltage (MV) distribution network based on substation-centralized scheme. A reliability assessment study such as SAIDI and AENSI was applied for automated distribution network. The results indicated clearly that reliability indices were reduced significantly. However, the complete structure and procedure of SC-FLISR were not clearly stated. Therefore, the proposed automated network was not reliable compared to non-automated network [13].

Eminoglu and Uyan (2016) presented the result of reliability indices obtained by analytical method for the Nigde Region's electricity systems. An approach based on the Monte Carlo (MC) simulation method was utilized to estimate the performance indices for the systems. The system reliability was evaluated for system's feeders and their load points. Reliability indices such as SAIFI and SAIDI were determined and simulated. Results obtained by the two approaches were presented and the reliability of system's feeders was discussed. The results showed that simulation was in close agreement with the analytical results. The implementation of the method used was very hard and complicated [15]. 
Pranitha and Chandrakala (2016) researched to reduce the real power losses in a real-time radial distribution system by performing Optimal Capacitor Placement (OCP) using GA to enhance the reliability of the system such as SAIFI, SAIDI and CAIDI. The method was implemented on $33 \mathrm{kV} / 415 \mathrm{~V}$ distribution system and the results of reliability analysis were compared with and without capacitor placement. Results illustrated that the increased value of sustained interruption system indices like SAIFI, SAIDI and preferably CAIDI indicated that the system was highly unreliable without capacitors. Whereas the results obtained after capacitor placement indicated reduction in real power losses and thus decrease of reliability indices value. However, the expected energy supplied to the consumer was not estimated with the reliability assessment [31].

Ahmed et al. (2017) presented the reliability indices such as SAIFI, SAIDI and CAIDI for appropriate guideline values of electric systems based on relation between indices and satisfaction area. The method was evaluated on electric network in Egypt to benchmark the performance and investments in generation, transmission and distribution network. The result indicated that the system planners and operators is a channel to improve the level of customer service. Nevertheless, the method cannot guarantee measuring the adequate and secure power supply for electric network performance [4].

Periyasamy (2017) analyzed the reconfiguration of distributed system along with simultaneous placement of Distribution Flexible AC Transmission System device (DFACTS) and Distributed Generations (DG) to improve the reliability of the system using Discrete Teaching-Learning Based Optimization (DTLBO) algorithm. The approach was tested on IEEE 33 and 69-bus radial distribution systems. The results showed that distribution system reconfiguration has a significant effect on reliability improvement. This proposed idea is well suited for different radial distribution systems but the method was only suitable for the location of single DG in distribution system [30].

\section{CONCLUSION}

The study has successfully reviewed different approaches used by previous researchers to study system reliability on electric power system using system reliability indices. From the reviewed, system reliability is normally stated in terms of the average values of the relevant reliability indices (System Average Interruptions Duration Index (SAIDI), System Average Interruptions Frequency Index (SAIFI) and Customer Average Interruptions Duration Index (CAIDI)). However, the study have shown that application of system reliability index in electrical power system for power system reliability assessment improved the stability of the system, thus, improve the power system performance. Therefore, this study has successfully provided expanded literature on performance of system reliability indices for power system reliability assessment.

\section{REFERENCES}

[1] Abdrabbi B and Meglouli, H. (2015). Reliability assessment of power distribution systems using disjoint path-set algorithm. Journal of Industrial Engineering International, 11(4), 45-57.

[2] Abul'Wafa A.R. (2016). Smart distribution system design: automation for improved reliability. Global Journal of Researches in Engineering: F Electrical and Electronics En, 16(7), 1-12.

[3] Ahadi A, Ghadimi N and Mirabbasi D. (2013). An analytical methodology for assessment of smart monitoring impact on future electric power distribution system reliability. Wiley Periodicals, Inc., 21(1), 99-113.

[4] Ahmed E, Abdualla S, Youssef K and Waheed H. (2017). Development of reliability indices for electric distribution network in Egypt. Renewable Energy and Sustainable Development, 3(1), 19-23.

[5] Ajenikoko G.A and Olaluwoye O.O. (2014). A generalized model for electrical power distribution feeders' contributions to system reliability indices. International Journal of Engineering Research, 3(11), 640-644.

[6] Ajenikoko G.A, Fakolujo O.A and Raji T.I. (2010). Reliability and quality assurance of electronic component.Journal of Engineering, Science and Technology, 5(2), 51-55.

[7] Barlow R. and Proschan F. (2001). Statistical theory of reliability and life testing probability models. IEEE Transactions on Power Systems, 19(7), 1126-1321.

[8] Billinton R. and Singh C. (2004): "System load representation in generating capacity reliability studies". The Nigerian Engineer, 19(1), 14-19.

[9] Bourezg A and Meglouli H. (2015). Reliability assessment of power distribution systems using disjoint pathset algorithm. Journal of Industrial Engineering International, 11(2), 45-57.

[10] Dan Z. (2003). Power system reliability analysis with distributed generators. IEEE Transactions on Power Systems, 6(12), 93-107.

[11] Das B and Deka B. (2013). Impact of distributed generation on reliability of distribution system. IOSR Journal of Electrical and Electronics Engineering, 8(1), 42-50.

[12] Elena N. Z and Vitaly G. L. (2001). Design of dynamic reliability indices. IEEE Transactions on power systems, 18(5), 39-51.

[13] Elkadeem M.R, Alaam M.A and Azmy A.M. (2016). Improving performance of underground MV distribution networks using distribution automation system: a case study. Ain Shams Engineering Journal, 
Production and hosting by Elsevier, 4(3), 1-13.

[14] Elsalmawy H, Youssef K, Abdulla S and Hussein S. (2011). Elementary evaluation of reliability indices for power system in Egypt. 21st International Conference on Electricity Distribution, 1(9), 1-4.

[15] Eminoglu U and Uyan R. (2016). Reliability analyses of electrical distribution system: a case study. International Refereed Journal of Engineering and Science, 5(12), 94-102.

[16] Endrenyi J and Billinton I.E. (2005). Reliability evaluation of transmission systems with switching after faults. IEEE transactions on Power Apparatus and Systems. 92(8),1863 - 1875.

[17] Feng, Z. (2006), "Electric distribution system risk assessment using actual utility reliability data", Master's Thesis, University of Saskatche wan, 4(7), 14-17.

[18] Gao L, Zhou Y, Li C and Huo L. (2014). Reliability assessment of distribution systems with distributed generation based on Bayesian networks. Engineering Review, 34(1), 55-62.

[19] Ge S, Xu L, Liu H and Zhao M. (2014). Reliability assessment of active distribution system using Monte Carlo simulation method. Hindawi Publishing CorporationJournal of Applied Mathematics, 10(11), 1-11.

[20] Gont S.D and Worku G.B. (2014). Assessment of power reliability and improvement potential by using smart reclosers. Journal of EEA, 31(3), 26-32.

[21] Hadow M.M, Abd Allah A.N and Abdul karim S.P. (2012). Reliability evaluation of distribution power systems based on Artificial Neural network techniques. Hindawi Publishing CorporationJournal of Electrical and Computer Engineering, 5(3), 1-6.

[22] Kahrobaee S. (2014). Reliability modeling and evaluation of distributed energy resources and smart power distribution systems. Theses, Dissertations, and Student Research from Electrical \& Computer Engineering, 54(3), 1-209.

[23] Kjølle G and Vefsnmo H. M. (2015). Customer interruption costs in quality of supply regulation: methods for cost estimation and data challenges. 23rd International Conference on Electricity Distribution, 7(14), 1-5.

[24] Kundur P. (2004). Power system stability and control. EPRI Power System Engineering Series, MC-Graw Hill. 6(5), 39-58.

[25] Lauby M and Billinton R. (2004): “A probabilistic method for transmission planning” In Proceedings of the 1998 International Conference on Probabilistic Methods Applied to Power Systems (PMAPS), Oakland, California. 7(6), 112-138.

[26] Mohan C.V, Seetharam K and Raju H.B. P. (2015). Reliability indices of distribution system by Fuzzy Method. International Journal of Science, Engineering and Technology Research (IJSETR), 4(7), 2444-2446.

[27] Neto A. C, Da Silva M. G. and Rodrigues A. B. (2006). Impact of distributed generations on reliability evaluation of radial distribution systems under network constraints. 9th International conference on probabilistic methods applied to power systems, KTH, Stockholm, Sweden, 4(5), 716-735.

[28] Noferi, P.I. and Paris I. (2004). Quantitative evaluation of power system reliability in planning studies. IEEE Transactions on Power Systems, 7(3), 416-438.

[29] Okorire P.U, Aliyu U.O, Jimoh B and Sani S.M. (2015). Reliability indices of electric distribution network system assessment. Quest Journals Journal of Electronics and Communication Engineering Research, 3(1), $1-6$.

[30] Periyasamy S. (2017). Distributed system reconfiguration with optimal allocation of DFACTS and DG for reliability enhancement using DTLBO algorithm. International Journal of Advances in Computer and Electronics Engineering, 2(5), $40-46$.

[31] Pranitha M. P and Chandrakala K.R.M. (2016). Optimal capacitor placement based improved reliability assessment of a distribution system. Indian Journal of Science and Technology, 9(30), 1-7.

[32] Rajaiah S, Satyanarayana V.S and Srinivas K. (2015). Evaluation and analysis of customer specific distribution reliability indices. Control Theory and Informatics, 5(1), 16-23.

[33] Roy B and Ronald A. (2006): "Reliability evaluation of power systems". Plenum Press, New York. 4(7), 3651.

[34] Roy B and Wenyuan L. (2004). Power system modeling, analysis and control. EPRI Power System Engineering Series, McGraw Hill, 4(5), 69-92.

[35] Sacket R. K, Bansal R. C and Singh C. O. (2007). Reliability evaluation of power system considering voltage stability and continuation power flow on power system. IEEE Transactions on Power Systems, 7(1), $258-$ 263.

[36] Sakis M.A.P, George C.J and Xing Y.C. (2005): A new probabilistic power analysis method. IEEE Transactions on Power Systems, 5(1), 182-190.

[37] Sindi H and El-Saadany E. (2016). Unified reliability index development for utility performance assessment developing a novel normalization-based index and comparing it with a fuzzy inference unified index. Intell Journal of Industrial System, 2(3), 149-161.

[38] Wang L. (2003). The effects of uncertainties in forced outage rates and load forecast on the loss-of load probability (LOLP). IEEE Transactions on Power Systems, 10(3), 306-328. 
[39] Wang P, Billinton R and Goel L. (2000). Probability distribution evaluation of distribution system reliability indices using a time sequential simulation technique. John Wiley and Sons, Inc. 4(6), 65-71. 